Revista de Economia Política, vol. 31, no 5 (125), pp. 730-750, Ediçã especial/2011

\title{
Finance-Led Growth Regime no Brasil: estatuto teórico, evidências empíricas e consequências macroeconômicas
}

\author{
MIGUEL BRUNO \\ HAWA DIAWARA \\ ELIANE ARAÚJO \\ ANNA CAROLINA REIS \\ MÁRIO RUBENS*
}

Finance-led growth regime in Brazil.

This paper analyzes the Brazilian growth pattern during the post-liberalization period, emphasizing the structural links between finance and productive capital accumulation. The results indicate a finance-led growth regime in the period 2004-2008, under a very specific financialization process. The first part is a survey of the international literature, which defines the financialization concept and its relevance for understanding Brazilian economic problems. The next part provides a historical overview on the structural changes that made possible the development of financial-led regimes. The paper also applies an empirical analysis of some selected Brazilian macroeconomic indicators.

Keywords: financialization; growth regime; Brazilian economy; Brazilian financial system.

JEL Classification: E44; O11; N26.

\footnotetext{
* Miguel Bruno, do IPEA, e-mail: miguel.bruno@ipea.gov.br, Hawa Diawara, da Universidade Federal do Rio de Janeiro, e-mail: diawara7@yahoo.fr; Eliane Araújo é professora do Departamento de Economia da Universidade Estadual de Maringá, e-mail: elianedearaujo@yahoo.com.br, Ana Carolina Reis é do IPEA, annacsaba@gmail.com; e Mário Rubens é da Fundação Getúlio Vargas, e-mail Mario.rubens@fgvmail.br. Submetido em 2/jul./2009; aprovado 29/mar./2010.
} 


\section{INTRODUÇÃO}

O artigo desenvolve uma abordagem do atual regime de crescimento da economia brasileira com base no conceito de financeirização (financialization/financiarisation). Seu principal objetivo é elucidar os vínculos estruturais e conjunturais entre a acumulação de base rentista-patrimonial e a acumulação de capital fixo produtivo, enquanto fator fundamental do crescimento e do desenvolvimento econômicos. Apesar de bastante difundidas no plano internacional, as pesquisas sobre o fenômeno da financeirização em seus efeitos macroeconômicos permanecem ainda escassas para o caso do Brasil.

As transformações estruturais dos anos 1990, incluindo o processo de estabilização de preços e de liberalização comercial e financeira, mudaram de um modo relativamente rápido a arquitetura institucional que suportava o padrão de crescimento por substituição de importações. Em consequência, a relação capital-trabalho, o relacionamento entre Estado e economia, e a forma de inserção internacional reconfiguraram-se sob as pressões dos mercados globais e sob interesses político-ideológicos que concorreram tanto no plano nacional quanto internacional, para elevar as finanças a uma posição dominante no que concerne às formas de revalorização dos capitais fora da esfera produtiva. Nessa perspectiva, a financeirização enquanto processo macroeconômico inaugura uma época peculiar em que as alternativas às imobilizações do capital são multiplicadas e sofisticadas graças às inovações financeiras e ao desenvolvimento das novas tecnologias da comunicação e da informação. Nesse ambiente macroeconômico, a possibilidade de enriquecimento privado através das alocações financeiras dos recursos disponíveis aos detentores de capital se materializou numa gama de produtos financeiros mais complexos (derivativos, swaps, títulos etc.), mas sem necessariamente encorajar o investimento produtivo em capital fixo. Dessa forma compreende-se que, nos países em que o processo de financeirização mais avançou, tenha ocorrido queda da participação do capital fixo produtivo no estoque de capital total, baixas taxas de crescimento e elevação do desemprego estrutural. Os estudos para o caso europeu e norte-americano são instrutivos quanto a essa questão (Aglietta, 2008 e 1999; Boyer, 2000 e 1999; Coriat, 2006; Stockhammer, 2007 e 2004), embora a economia dos Estados Unidos tenha apresentado um padrão de financeirização com características próprias.

Entre as principais hipóteses deste trabalho está a proposição de que a financeirização na economia brasileira é também muito peculiar, desenvolvendo-se sobre a base da renda de juros e tendo como eixo o endividamento público interno. Nas economias desenvolvidas, a financeirização tende a se desenvolver através do endividamento privado e sob taxas reduzidas de juros, pois é o mercado de capitais o locus da revalorização rentista. Compreendem a estrutura deste artigo, além da presente introdução, três seções e uma conclusão. A primeira seção proporciona um exame da literatura internacional sobre o conceito de financeirização, explicitando 
seu estatuto teórico e relevância para as macroanálises do crescimento econômico. A segunda seção faz um panorama das transformações estruturais e institucionais na economia mundial que permitiram o advento e consolidação desse processo. A terceira seção desenvolve uma análise empírica para o caso brasileiro a fim de elucidar os determinantes do regime de crescimento que emerge quando as condições de produção e de circulação estão subordinadas à lógica da acumulação financeira.

\section{FINANCEIRIZAÇÃO: ORIGENS DO CONCEITO E ESTATUTO TEÓRICO}

Segundo Braga (1985), a financeirização é definida como uma norma sistêmica de riqueza, na medida em que ela produz uma dinâmica estrutural articulada segundo os princípios da lógica financeira ${ }^{1}$. Mais especificamente, essa norma de riqueza determina as formas contemporâneas de produzir a acumular a riqueza. Ela não resulta apenas de práticas de segmentos ou de setores específicos (representados tradicionalmente pelo capital bancário e pelos rentistas), mas caracteriza, em âmbito global, as estratégias de todos os agentes privados relevantes (grandes corporações industriais, famílias, Banco Central, Tesouro Nacional etc.). Nesse sentido, a financeirização condiciona as operações de financiamento e de despesas públicas, modificando a dinâmica macroeconômica.

Do ponto de vista do debate acadêmico, a noção de financeirização foi introduzida a fim de proporcionar uma perspectiva crítica para os pressupostos fundamentais da teoria convencional, em especial sua concepção do papel dos mercados financeiros sobre a hipótese de eficiência alocativa (Palley, 2007). A financeirização apresenta, portanto, uma visão alternativa dos mercados financeiros, não mais através do paradigma da eficiência alocativa, mas sim no contexto do sistema econômico como um todo. Os mercados financeiros são considerados um subconjunto do sistema econômico que "distribui o poder" e afeta a dinâmica da produção e distribuição de renda.

As diferentes abordagens do processo de financeirização podem ser divididas em duas partes, uma que analisa esse processo em nível macrossetorial, e outra em termos microeconômicos. A primeira abordagem investiga os mecanismos de financeirização mediante a integração das estratégias do conjunto dos diferentes atores sociais e econômicos. Já a segunda abordagem concentra-se no comportamento de um único setor e enfatiza as estratégias das grandes corporações industriais e suas implicações sobre o modo de gestão do trabalho assalariado. A abordagem macros-setorial pode ser subdividida ainda em três subcategorias: i) a análise histórico-estrutural, ii) a análise regulacionista e iii) as demais abordagens sobre o tema.

O Quadro 1 sintetiza as características dessas diferentes abordagens.

\footnotetext{
${ }^{1}$ A escolha por esta definição deve-se a sua abrangência e à consideração da iniciativa pioneira de Braga em sua tese: Temporalidade da riqueza: teoria da dinâmica e financeirização do capitalismo.
} 
Quadro 1: diferentes abordagens do processo de financeirização

\begin{tabular}{|c|c|c|}
\hline AUTOR & ENQUADRAMENTO TEÓRICO & Análise empírica \\
\hline \multicolumn{3}{|c|}{ ABORDAGEM MACRO-SETORIAL: Análise historico-estruturalista } \\
\hline BRAGA (1998) & $\begin{array}{l}\text { Parte do conceito de capital } \\
\text { financeiro de Hilferding (1963) } \\
\text { para compreender como os } \\
\text { agentes econômicos monetizam } \\
\text { a riqueza financeira. }\end{array}$ & $\begin{array}{l}\text { O processo de financeirização } \\
\text { se manifesta por uma defasa- } \\
\text { gem, crescente e recorrente, } \\
\text { entre o valor dos papéis que } \\
\text { representam a riqueza, o valor } \\
\text { dos bens e serviços e as ba- } \\
\text { ses técnico-produtivas de uma } \\
\text { sociedade. }\end{array}$ \\
\hline SALAMA (1999) & $\begin{array}{l}\text { Faz referência à teoria do ciclo } \\
\text { do capital de Marx e retoma a } \\
\text { hipótese sobre as origens do va- } \\
\text { lor. Também se inspira na teoria } \\
\text { keynesiana para compreender a } \\
\text { condução da política econômica. }\end{array}$ & $\begin{array}{l}\text { O grau de financeirização de } \\
\text { uma nação ou de uma empre- } \\
\text { sa é mensurado pelo seguinte } \\
\text { indicador: Ativos financeiros / } \\
\text { Ativos totais (ativos financeiros } \\
\text { e reais). }\end{array}$ \\
\hline \multicolumn{3}{|c|}{ ABORDAGEM MACROSSETORIAL: Análise regulacionista } \\
\hline BOYER (2000) & $\begin{array}{l}\text { Insere-se no contexto geral da } \\
\text { Teoria da Regulação. A macroe- } \\
\text { conomia keynesiana é também } \\
\text { utilizada para construir um } \\
\text { modelo representativo de uma } \\
\text { economia simplificada. }\end{array}$ & $\begin{array}{l}\text { São estimados para Estados } \\
\text { Unidos, Inglaterra, Canadá, } \\
\text { Japão diferentes parâmetros } \\
\text { representativos da financei- } \\
\text { rização: fração da riqueza } \\
\text { sob a forma de ações / renda } \\
\text { disponível; e fração de ações e } \\
\text { obrigações / capital financeiro } \\
\text { das famílias. }\end{array}$ \\
\hline BRUNO (2007) & $\begin{array}{l}\text { Retoma a hipótese de hierarqui- } \\
\text { zação das formas institucionais } \\
\text { da teoria da regulação, assim } \\
\text { como a hipótese dos autores } \\
\text { clássicos que relaciona a forma } \\
\text { de repartição do excedente eco- } \\
\text { nômico com o ritmo de acumula- } \\
\text { ção do capital. }\end{array}$ & $\begin{array}{l}\text { Realiza uma análise setorial } \\
\text { para a economia brasileira a } \\
\text { partir da evolução da estrutura } \\
\text { patrimonial das empresas } \\
\text { não financeiras e da análise } \\
\text { macroeconômica por meio da } \\
\text { construção do indicador: fluxo } \\
\text { de juros recebido pelo setor } \\
\text { bancário e financeiro / produto } \\
\text { interno bruto. }\end{array}$ \\
\hline \multicolumn{3}{|c|}{ ABORDAGEM MACROSSETORIAL: Outros trabalhos empíricos } \\
\hline EPSTEIN (2001) & $\begin{array}{l}\text { Busca entender os quatro fato- } \\
\text { res determinantes da política } \\
\text { do Banco Central (BC): i) a re- } \\
\text { lação de força capital/trabalho } \\
\text { e a relação produtos/mercado; } \\
\text { ii) a estrutura política do BC; iii) } \\
\text { a relação finanças/indústria; e } \\
\text { iv) o posicionamento da nação } \\
\text { na economia mundial. }\end{array}$ & $\begin{array}{l}\text { Apresenta um modelo de } \\
\text { Banco Central e o estima } \\
\text { para a economia americana } \\
\text { na década de } 1960 .\end{array}$ \\
\hline
\end{tabular}




\begin{tabular}{|c|l|l|}
\hline \multirow{5}{*}{ KRIPPNER ((2005) } & $\begin{array}{l}\text { A evidência empírica do } \\
\text { processo de financeirização } \\
\text { necessita conjugar uma abor- } \\
\text { dagem setorial com uma abor- } \\
\text { dagem extrassetorial. }\end{array}$ & $\begin{array}{l}\text { Dois indicadores de financeiriza- } \\
\text { ção são apresentados: i) lucros } \\
\text { gerados no setor financeiro / } \\
\text { lucros gerados no setor não fi- } \\
\text { nanceiro e ii) rendas de portfólio } \\
\text { / Cash Flow. Estes são estima- } \\
\text { dos para a economia americana } \\
\text { durante no período 1950-2000. }\end{array}$ \\
\hline STOCKHAMMER (2007) & $\begin{array}{l}\text { Parte de uma função de de- } \\
\text { manda agregada para analisar } \\
\text { a relação entre financeirização } \\
\text { e transformação dos compor- } \\
\text { tamentos macroeconômicos. }\end{array}$ & $\begin{array}{l}\text { Estima as funçães de comporta- } \\
\text { mento (consumo, investimento, } \\
\text { exportaçós líquidas e déficit } \\
\text { público) para o conjunto das } \\
\text { economias desenvolvidas entre } \\
\text { 1970 e 2000. }\end{array}$ \\
\hline ABORDAGENS MICROECONÔMICAS: Governança Corporativa e relações de trabalho
\end{tabular}

Fonte: Elaboração própria.

\section{FINANCEIRIZAÇÃO E CRESCIMENTO ECONÔMICO: AMBIGUIDADES DA RELAÇÃO ENTRE ACUMULAÇÃO RENTISTA E PERFORMANCE MACROECONÔMICA}

Um regime de crescimento no qual a circulação monetária e financeira, e não a alocação diretamente produtiva, torna-se a base da revalorização dos capitais é classificado como finance-dominated accumulation regime. Proposto por Stockhammer (2007), este último conceito não pressupõe, necessariamente, uma correlação positiva entre a acumulação financeira e a acumulação de capital fixo pro- 
dutivo, mas não a exclui. Em determinadas condições estruturais e conjunturais, esse padrão pode se converter num finance-led growth regime, caso em que o efeito-riqueza e o efeito-acelerador do investimento se revelam importantes para comandar a compatibilidade dinâmica entre produção e demanda agregada. No entanto, as condições de estabilidade ou a sustentabililidade desse regime não estão garantidas a priori e, a depender do cenário internacional e dos fatores que afetam o mercado interno de consumo, podem mesmo se revelar efetivamente problemáticas. A economia brasileira é exemplo típico para esses dois casos. Por apresentar elevada volatilidade da taxa de investimento, manteve-se numa dinâmica cíclica do tipo stop and go, entre início dos anos 1990 até 2003. Porém, a partir de 2004, consegue reencontrar uma nova trajetória de expansão das taxas de acumulação de capital, que se refletirá em taxas mais elevadas de crescimento econômico. Mas essa trajetória é interrompida no quarto trimestre de 2008, quando a economia brasileira seria efetivamente afetada pela propagação da crise americana. Essas considerações trazem naturalmente à análise os problemas de previsibilidade das performances macroeconômicas, quando as economias estão submetidas a um processo de financeirização.

\section{Fatos estilizados da financeirização na economia brasileira}

a) Lucro e acumulação em três diferentes fases de evolução

Um segundo fato estilizado relevante por sua implicação para a dinâmica do crescimento econômico brasileiro refere-se aos três padrões de evolução das taxas de lucro e de acumulação de capital fixo produtivo, observado no Gráfico 2. Durante a vigência do modelo de industrialização substitutiva de importações, as análises empíricas revelaram a existência de um regime do tipo profit-led growth porque o investimento era impulsionado pelos aumentos das taxas de lucro (Bruno, 2005). Essas duas séries compartilharam inclusive uma tendência comum de evolução no período 1966-1993 e permaneceram nitidamente em correlação positiva. Observa-se, porém, um período de crescimento (1966-1975) e, em seguida, de queda conjunta dessas variáveis, expressão dos desdobramentos da crise do regime de crescimento do "milagre" com as dificuldades estruturais e conjunturais ao longo dos anos 1980. Todavia, a partir de 1994, o padrão de evolução é muito diferente, destacando-se duas outras fases. Uma fase de estagnação relativa, quando as taxas de lucro e de acumulação se desconectam. A primeira variável mantendo-se em uma trajetória de crescimento enquanto a segunda permanecia praticamente estagnada. Como um resultado macroeconômico direto, o crescimento econômico apresentou-se muito instável e sob taxas muito baixas, relativamente à média histórica. A terceira e última fase revela que essas duas variáveis voltam a 
apresentar trajetórias de expansão. Mas, de fato, foi a taxa de acumulação de capital fixo produtivo que voltou a crescer de um modo rápido (média de 7,8\% ao ano entre 2004 e 2008), pois a taxa de lucro já estava em expansão desde 1999, com crescimento médio anual de $1,8 \%$.

Gráfico 1: Taxa média de lucro e taxa de acumulação (1966-2008)

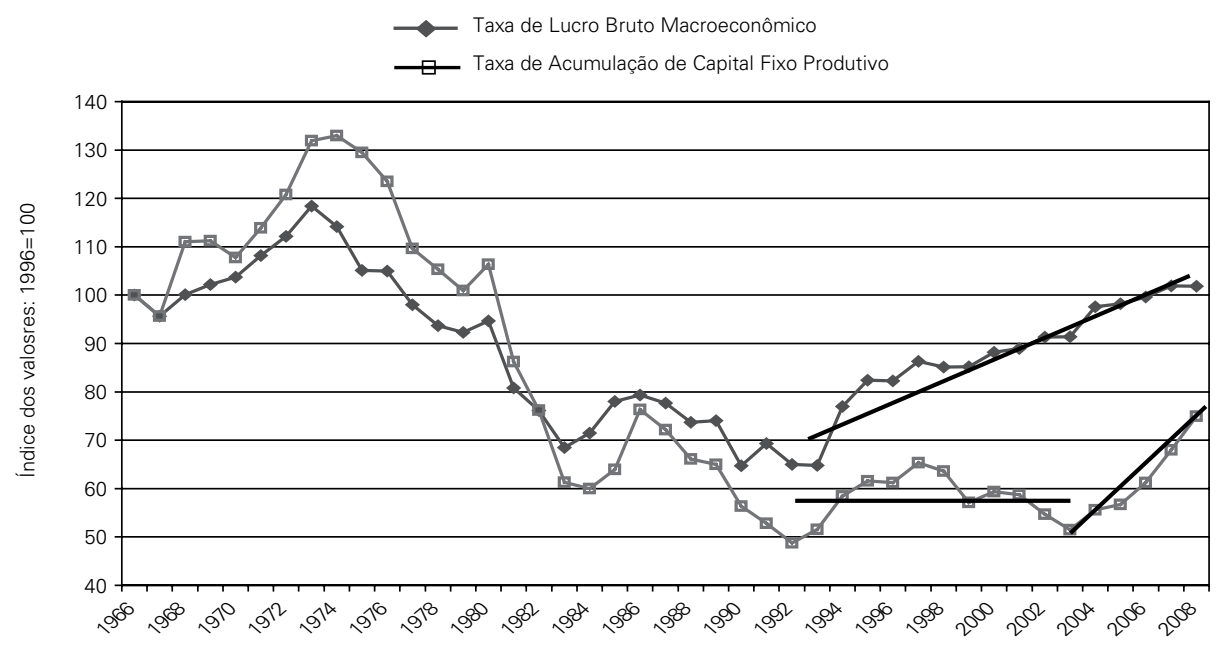

Fonte: IBGE e Marquetti (1998).

b) Declínio tendencial da proporção do lucro macroeconômico alocada em ativos fixos

Pelo Gráfico 2 pode-se constatar o declínio tendencial da parcela do lucro bruto macroeconômico destinada à formação bruta de capital fixo (FBCF/Lucro), a partir de 1975. Simultaneamente, pode-se inferir que a parcela destinada a outros ativos foi em parte alocada em operações financeiras e em parte consumida. Observe-se que apenas a partir de 2004 é que a parcela destinada à FBCF interrompe sua trajetória de queda, voltando a crescer em 2006, o que explica a melhor performance do crescimento econômico dos últimos três anos. Este fato reforça a hipótese de que o regime de acumulação brasileiro teria assumido um padrão típico de finance-led growth, em que as decisões de investimento são “comandadas", prioritariamente, pela norma de rentabilidade real ofertada pelos mercados financeiros. 
Gráfico 2: Taxa de financeirização e alocação do lucro macroeconômico (1974-2008)

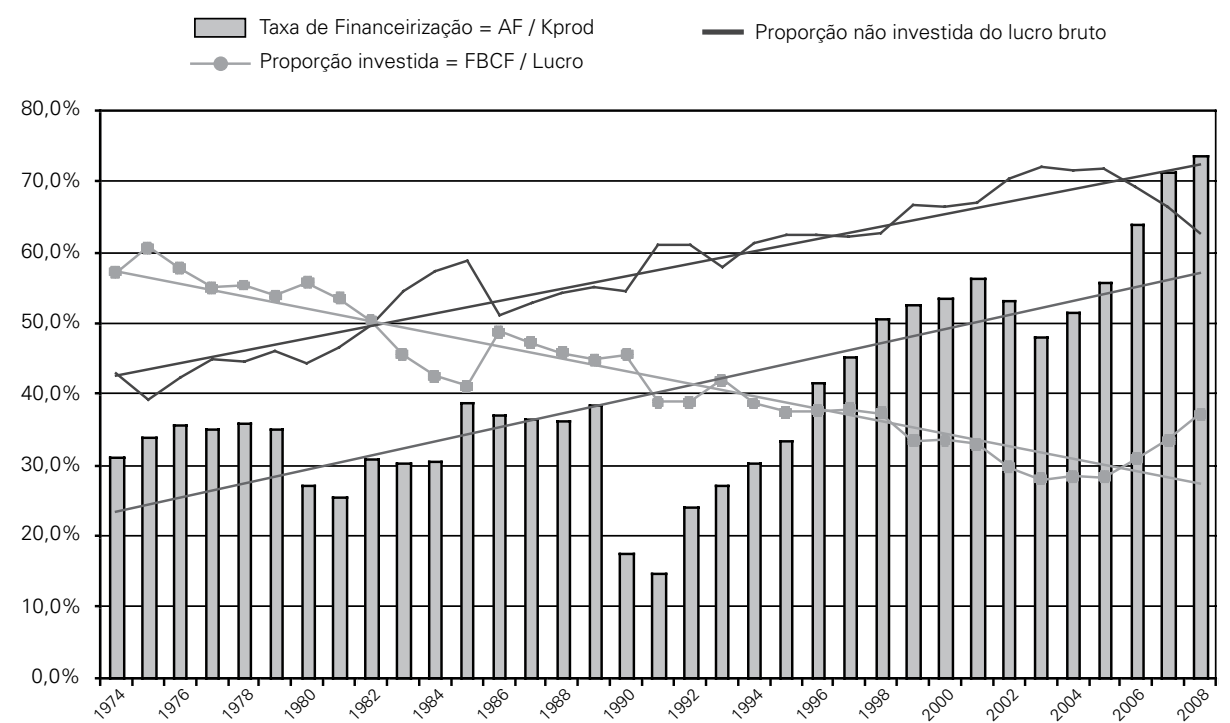

Fonte: IBGE, IPEADATA (2009) e Marquetti (2003).

Nota: A taxa de financeirização corresponde à proporção entre o estoque total de ativos financeiros (AF) e o estoque total de capital fixo produtivo (Kprod).

c) Taxa de financeirização e proporção não investida do lucro médio em correlação positiva

Um indicador usual de financeirização no plano macroeconômico é construído pela razão entre o total de ativos financeiros não monetários $(A F)$, dado pela diferença entre os agregados monetários M4 e M1 (deflacionados pelo IGP-DI) e o estoque total de capital fixo produtivo líquido de depreciação, isto é, máquinas e equipamentos mais construções não residenciais (Kprod). A relevância desta relação é que ela expressa, no plano macroeconômico, a arbitragem entre a alocação diretamente produtiva da poupança empresarial e sua alocação financeira. Consequentemente, a proporção não investida do lucro macroeconômico corresponde às frações consumidas e alocadas em ativos financeiros por firmas e detentores de capital.

No Gráfico 2 pode-se constatar também que a taxa de financeirização evolui em correlação positiva com a parcela do lucro médio não investida produtivamente, pois a lógica da financeirização se expressa precisamente na existência, sofisticação e generalização de um leque amplo de ativos líquidos e rentáveis que competem com as imobilizações de capital exigidas pelas atividades diretamente produtivas. Esses dois indicadores permanecem em tendências nítidas de crescimento, representadas pelas linhas ajustadas às séries originais. Novamente, o destaque vai para o último período, 2004-2008, em que a correlação se inverte e, apesar do 
crescimento da taxa de financeirização, a parcela não investida declina, pois a $F B C F$ voltou a crescer nesses anos.

d) Declínio tendencial e estagnação da participação do estoque de capital fixo produtivo no estoque fixo total

A participação das máquinas e equipamentos declina tendencialmente desde 1976, de acordo com o Gráfico 3. Uma expressão do esgotamento e crise do regime de acumulação responsável pelo "milagre econômico" brasileiro. As construções não residenciais, que incluem o estoque de capital fixo correspondente às infraestruturas, aumentaram sua participação até 1994; desde então se observa estagnação relativa desse indicador, com nítida queda de participação a partir de 2004.

Gráfico 3: Componentes do estoque de capital fixo total (1950-2008)

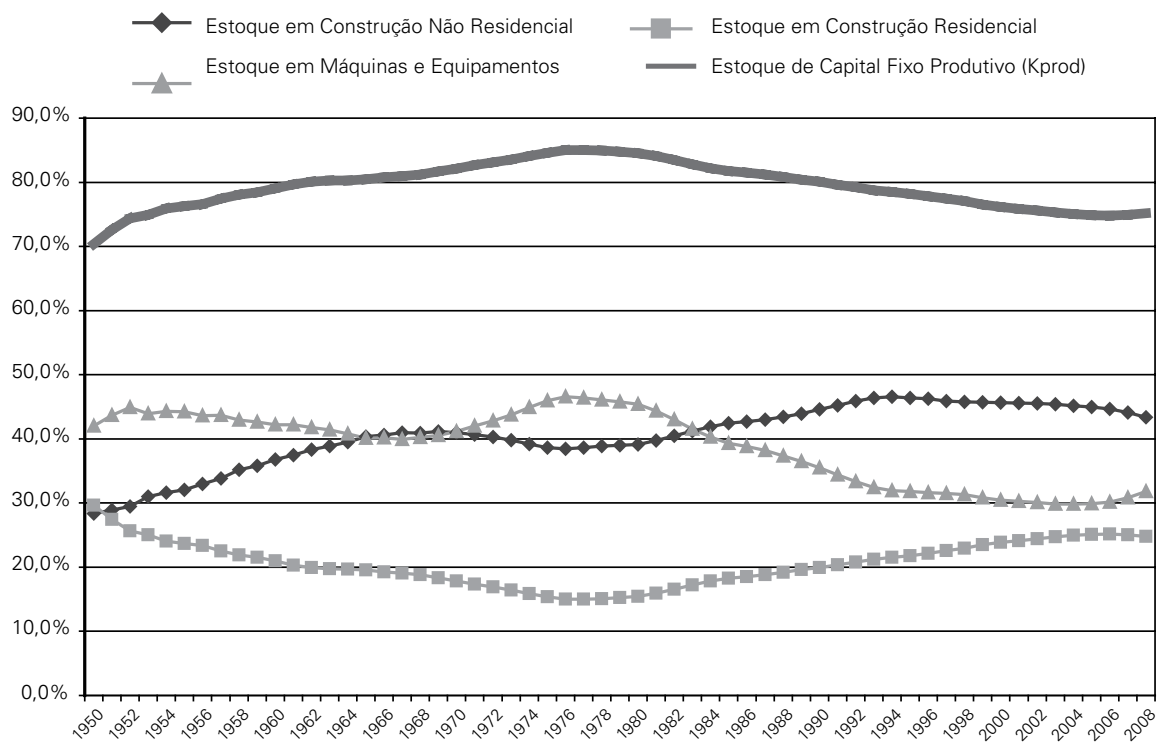

Fonte: IPEADATA (2009)

Observe-se que o modelo de crescimento pós-Real e pós-liberalização levou cerca de 14 anos para estabilizar a participação do estoque em máquinas e equipamentos que, no entanto, permanece 32\% abaixo do pico alcançado em 1976.

Poder-se-ia contra-argumentar que o estoque de capital fixo atual possui conteúdo tecnológico superior e assim pode crescer a taxas mais baixas do que as vigentes no modelo de industrialização por substituição de importações. O problema é que, nesse caso, o ritmo de geração de emprego é comprometido, condenando a economia brasileira a níveis elevados de desemprego estrutural e freando a dinâmica da demanda efetiva no médio ou longo prazo. 
A hipótese de que, no período 1980-1993, a economia brasileira esteve sujeita a um processo de financeirização baseado nos ganhos inflacionários derivados dos mecanismos institucionais de correção monetária e de indexação generalizada de preços e salários encontra apoio na análise empírica proposta. Consequentemente, como é o caso para vários fenômenos em economia, a financeirização em suas dimensões micro e macroeconômicas pressupõe um ambiente institucional específico, e sem o qual esse processo não pode emergir e se desenvolver. Um regime monetário-financeiro dual e inflacionista pôde se consolidar ao longo dos anos 1980 e ao mesmo tempo em que proporcionava relativa proteção aos agentes econômicos contra uma inflação crescente, contribuía para reproduzi-la através da institucionalização da moeda indexada. A dualidade provinha precisamente da coexistência de duas moedas: a) a moeda oficial emitida pelo Estado no conceito de $M 1$; e b) a moeda financeira-indexada que era lastreada pelos títulos públicos, mas gerida e emitida endogenamente pelo setor financeiro privado. A primeira funcionando como unidade de conta e meio de pagamento e a segunda como reserva de valor e instrumento de enriquecimento privado, a partir de ativos de alta liquidez e rentabilidade com baixo risco. Operava-se assim uma dissociação das funções da moeda que estava na base da acumulação rentista e do processo de financeirização por inflação, ao mesmo tempo que adiava a irrupção violenta de uma hiperinflação clássica.

Para sustentar a hipótese de existência do RMF dual enquanto base da financeirização por inflação, foi realizada uma análise econométrica da relação entre o valor adicionado $(V A)$ das instituições financeiras e o PIB brasileiro. Os dados indicam que, a partir de 1970, quanto maiores as taxas de inflação maior a participação do sistema financeiro no valor adicionado total da economia brasileira. Consequentemente, as consideradas décadas perdidas certamente não o foram para este setor. Esse fato é inclusive reconhecido pelas autoridades monetárias brasileiras. Resta investigar, contudo, a possível existência de causalidade entre essas variáveis.

Os testes de raízes unitárias e de Johansen indicam que as séries da inflação medida pelo IGP-DI e o VA financeiro como porcentagem do PIB são não estacionárias e cointegram no período 1964-1993, expressão da existência de uma relação de equilíbrio de longo prazo entre essas variáveis. Esse equilíbrio não deve ser interpretado de modo usual em economia, isto é, como um resultado da compatibilidade entre oferta e demanda. O fato de essas duas séries compartilharem uma tendência de evolução comum pode ser interpretado como o resultado macroeconômico derivado de uma estrutura organizacional ou de uma institucionalidade específica do regime monetário e do sistema financeiro vigentes neste período. $\mathrm{O}$ cálculo da elasticidade-inflação de longo prazo do VA financeiro mostra que um aumento de $10 \%$ nas taxas de inflação leva a um aumento médio de $3,4 \%$ da participação do VA financeiro no PIB.

A cointegração conduz naturalmente à investigação da existência de vínculos causais entre essas variáveis. O teste de causalidade de Granger revela que as va- 
riações das taxas de inflação precedem as variações no VA financeiro, mas o oposto não foi estatisticamente significativo. Esse resultado mostra a funcionalidade dos ganhos inflacionários para a expansão financeira observada no período 1964-1993.

\section{Um RMF à elevada restrição monetária e o novo padrão de financeirização pela renda de juros (1995-2008)}

A redução forte e rápida da inflação e, portanto, dos ganhos inflacionários no período pós-Real, em um ambiente de liberalização financeira e de mercados globais, desencadeou um processo de mudança estrutural no sistema bancário-financeiro brasileiro. Sob esse novo regime monetário-financeiro não inflacionista, o novo eixo da acumulação financeira vai se deslocar em direção aos derivativos e títulos de renda fixa conectados ao endividamento público, mas agora sob taxas reais de juros extremamente elevadas pelos padrões internacionais. Os ganhos inflacionários seriam então rápida e facilmente substituídos pela renda de juros somada aos retornos com ativos financeiros transacionados em escala internacional.

Partindo-se dos dados do Plano Contábil das Instituições Financeiras-COSIF, elaborado pelo Banco Central do Brasil, pode-se constatar que a rentabilidade real com elevada liquidez oferecida pelos ativos de renda fixa, e os derivativos que lhes são associados, respondem por praticamente $50 \%$ da receita operacional total do sistema bancário-financeiro, para o período 1995-2006. Como as receitas de operações de crédito não ultrapassam os $20 \%$, torna-se, portanto, clara a razão pela qual as instituições financeiras privadas brasileiras não estão propensas a expandir o sistema de crédito em níveis compatíveis com as necessidades do setor produtivo e, portanto, com o desenvolvimento econômico nacional.

Dados apresentados em Bruno (2008) mostram que os fluxos de juros recebidos e pagos pelo sistema financeiro brasileiro permaneceram, respectivamente, numa média de $29,4 \%$ e de $22,2 \%$ do PIB, para o período $1993-2005$. A diferença entre esses dois fluxos $(7,1 \%)$ corresponde à parcela efetivamente retida pelo sistema bancário-financeiro, enquanto os $22,2 \%$ correspondem ao montante apropriado pelas famílias detentoras de capital e pelas empresas não financeiras. Esses últimos agentes assumem assim um comportamento claramente rentista. Destaque-se que são os $29,4 \%$ que proporcionam uma medida do grau de financeirização por juros da economia brasileira, e não a participação do valor adicionado das instituições financeiras no PIB do país. Contudo, deve ser destacado que essa participação capta apenas a renda de juros apropriada pelas instituições financeiras, e, portanto, não é um bom indicador de financeirização.

Consequentemente, a queda acentuada do valor adicionado (VA) financeiro no PIB, a partir da vigência do Real, não é expressão do fim do processo de financeirização ou de seu enfraquecimento na economia brasileira, mas sim da mudança das condições estruturais de seu desenvolvimento, que se fariam, doravante, com base em novos ativos, num contexto de liberalização financeira, de baixa inflação e de política monetária restritiva. 
- A vinculação estrutural entre dívida pública interna e renda de juros

A dívida pública interna tem sido o principal eixo da acumulação rentista-patrimonial no período 1991-2008, mas de uma maneira mais explícita. De fato, no período pré-liberalização dos anos 1980, a crise fiscal do Estado brasileiro já se articulava com as principais regularidades macroeconômicas que permitiam à acumulação financeira desenvolver-se a partir dos ganhos inflacionários e das tendências à estagnação do produto. Mas o próprio ambiente de crise com alta inflação ocultava, de certa forma, a funcionalidade do endividamento público para a expansão financeira.

Quanto às trajetórias da dívida pública interna e externa líquidas como porcentagens do PIB, observe-se segundo dados do Banco Central (2009) que a razão dívida pública interna líquida / PIB expande-se numa tendência aproximadamente linear, com crescimento médio mensal de cerca de 0,5\% entre 1991-2009 (ou de $4,8 \%$ anual no período pós-Real). Em consequência, esse indicador alcançou $52 \%$ do PIB em dezembro de 2009, enquanto em janeiro de 1991 representava apenas 17,4\%. Essa evolução sugere a possibilidade de uma trajetória explosiva para essa variável, uma vez que as quedas da razão dívida/PIB dão-se momentaneamente, pois logo em seguida retomam a tendência de crescimento de longo prazo. A hipótese da financeirização como um processo resultante de condições macroeconômicas específicas implica considerar que a macroestrutura financeira atualmente vigente na economia brasileira aprisiona as finanças públicas porque comanda a política monetária e fiscal, formatando-a segundo as prerrogativas da acumulação rentista. Por essa razão, pode-se considerar de um lado a endogeneidade da dívida pública no modelo econômico neoliberal e, de outro, a exogeneidade da taxa Selic, uma vez que esta se converteu em instrumento-chave da política monetária restritiva inerente à financeirização por renda de juros. Isso significa que, contrariamente à vulgata acerca de um comportamento supostamente perdulário do Estado brasileiro, são os gastos financeiros, permanentemente realimentados por altíssimas taxas de juros reais, que respondem pelo crescimento da dívida pública interna.

O Gráfico 4 mostra a forte correlação positiva entre o crescimento do estoque da dívida pública interna, a preços constantes, e o fator acumulado da taxa real de juros Selic, que expressa a capitalização composta, praticada pelos mercados financeiros. Destaque-se que um aplicador que tivesse adquirido um título indexado à Selic em janeiro de 1991 e não o vendesse, teria, em janeiro de 2009, seu capital multiplicado por mais de 7 vezes. Trata-se de uma espetacular renda de juros, muito acima dos padrões internacionais, mesmo para uma economia ainda em desenvolvimento. Mas a questão dos vínculos causais entre essas variáveis é relevante para a sustentação empírica das hipóteses propostas neste trabalho. Uma análise econométrica para o período 1996-2009 revela que essas variáveis cointegram, desfrutando de uma tendência comum de evolução. Além disso, os testes de causalidade de Granger revelaram que as variações da taxa de juros Selic precedem as variações na dívida pública, apontando para a existência de causalidade unilateral da renda de juros para a expansão do endividamento do setor público brasileiro. 
$\square$ Estoque da Dívida Pública Interna (esq.)

$\longrightarrow$ Fator Acumulado da Taxa Selic Real (dir.)

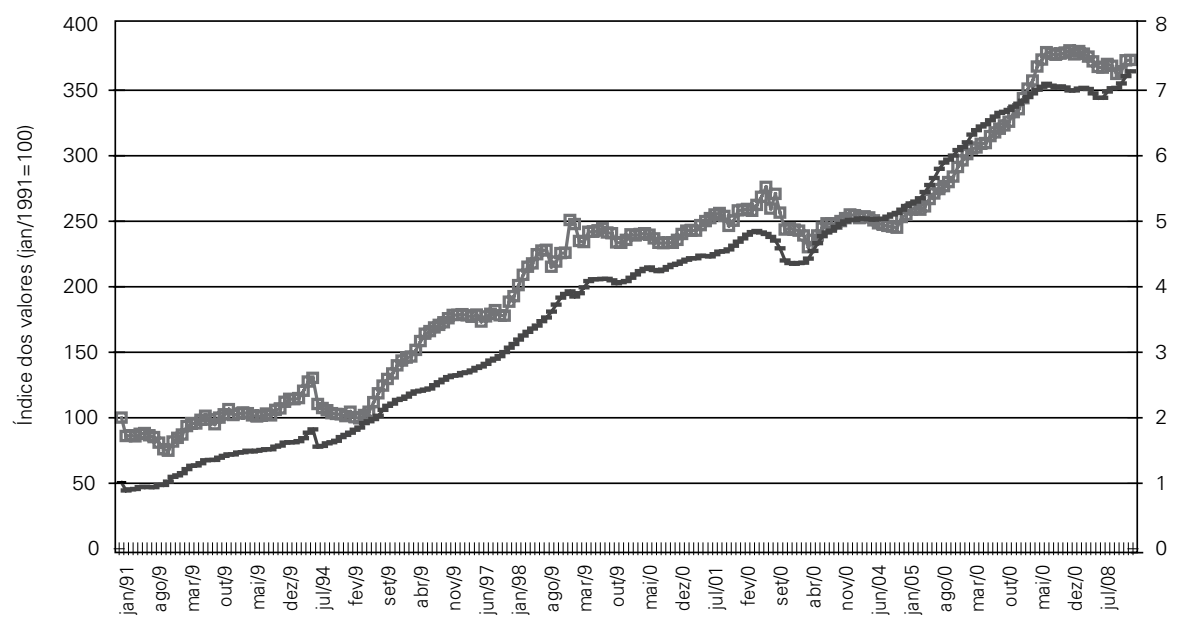

Fonte: IBGE e IPEADATA (2009).

Destaque-se com base nos dados do COSIF-BCB (2009) que a renda de títulos e valores imobiliários responde por mais de $84 \%$ da receita operacional total desse setor, enquanto as operações de crédito ao consumo e ao investimento produtivo representam apenas $10 \%$. Essa alta participação da renda com títulos e valores mobiliários (que inclui títulos de renda fixa, renda variável e operações com derivativos) segue a tendência de crescimento do fator acumulado da taxa Selic real. Trata-se, portanto de um sistema financeiro disfuncional no que concerne à promoção do crédito e do financiamento do crescimento econômico, mas altamente eficiente em promover a renda de juros e sua apropriação por parte dos segmentos diretamente beneficiados pelo processo de financeirização da economia brasileira. Nessas condições é compreensível que o autofinanciamento seja uma prática recorrente das empresas brasileiras, sobretudo as que não têm acesso às melhores linhas de crédito ofertadas pelos bancos públicos.

A formação bruta de capital fixo (FBCF) em dois padrões contrastados, mas comandados pela financeirização

A dinâmica do investimento produtivo no Brasil permaneceu nitidamente cíclica até 2003, minando as bases para um crescimento econômico forte e sustentável (Gráfico 5). A partir de 2004, a formação bruta de capital fixo entra em uma trajetória mais regular de expansão, sugerindo a entrada da economia brasileira em um novo regime de crescimento. 
Gráfico 5: Investimento e seus componentes: taxa de variação acumulada em quatro trimestres (1997-2008)



Fonte: IPEADATA (2009).

Para testar a influência desse tipo de financeirização baseado na renda de juros sobre o comportamento da taxa de acumulação de capital fixo produtivo, foi estimado um modelo baseado em Stockhammer (2007), que se utiliza das seguintes variáveis explicativas da taxa de acumulação de capital: o nível de utilização da capacidade instalada (que capta a influência da demanda sobre as decisões de investimento), a taxa de lucro (porque capta o retorno esperado do investimento produtivo), uma proxy do custo de uso do estoque de capital fixo produtivo por parte das firmas, e a participação da renda financeira no PIB, para detectar os efeitos da financeirização. Por simplificação, e porque é difícil encontrar os mesmos dados para o Brasil, será utilizado como indicador sintético para essas duas últimas variáveis explicativas a razão entre o fator acumulado da taxa Selic real e o estoque de capital fixo produtivo. Acredita-se que esse seja um bom indicador de como a renda financeira pode afetar as decisões de investimento produtivo, uma vez que quanto maior a renda de juros capitalizada (via fator acumulado da taxa Selic) relativamente ao volume de capital imobilizado em máquinas e equipamentos pelas empresas, menor seria o estímulo para ampliarem esse volume ou para expandirem a capacidade produtiva instalada. Caso em que é melhor aplicar suas receitas em ativos financeiros. E é isso o que a financeirização induz, uma vez que esse processo se reproduz pela existência de um leque amplo de alternativas de revalorização dos capitais na circulação monetária e financeira. Em termos keynesianos, a financeirização exacerba a preferência pela liquidez dos detentores de capital, elevando a taxa de retorno dos projetos de investimento nas atividades produtivas. E por essa razão, esse processo desloca a rentabilidade média de referência do setor produtivo para o setor financeiro. Portanto, o modelo aqui testado coloca a taxa de acumulação de capital $(\mathrm{G})$ como uma função da taxa de lucro empresarial $(\mathrm{R})$, da rentabilidade financeira $(\mathrm{F})$ e do nível de utilização da capacidade instalada (U). O Gráfico 6 permite uma visualização do comportamento dessas séries, sugerindo a existência de relações estruturais entre lucro, acumulação de capital e renda financeira. 
Gráfico 6: Lucro empresarial, rentabilidade financeira, acumulação de capital e utilização de capacidade (1991-2008)



Fonte: Cálculos próprios a partir das séries do IPEADATA.

Nota: Variáveis dessazonalizadas e em índices dos valores.

A estimativa dessa relação é feita para o período entre o segundo trimestre de 1991 e o terceiro trimestre de 2008. A primeira etapa foi a realização do teste de raiz unitária e a constatação de que as variáveis são não estacionárias, além de serem cointegradas. A partir disso, aplicou-se o teste de quebra estrutural à relação sugerida anteriormente, constatando-se que há uma quebra estrutural no primeiro trimestre de 2004. Sendo assim, optou-se por estimar o modelo em duas etapas, uma de 1991 a 2003 e outra de 2004 a 2008.

Na primeira etapa, a elasticidade de longo prazo estimada pelo vetor de correção de erros encontra-se na Tabela 1 .

Tabela 1: Equação da acumulação de capital (1991-2003)

\begin{tabular}{lccccc}
\hline Eq. De Cointegração & $G(-1)$ & $F(-1)$ & $R(-1)$ & $U(-1)$ & $C$ \\
\hline & 1 & 0.54839 & -0.278245 & 4.742033 & -18.56853 \\
Erro-padrão & & -0.23505 & -0.12286 & -1.25152 & \\
Teste t & & {$[-2.33313]$} & {$[2.26473]$} & {$[-3.78901]$} & \\
\hline
\end{tabular}

Fonte: Elaboração própria.

Nessa primeira fase, a rentabilidade do investimento influencia negativamente a taxa de investimento enquanto o fator acumulado da Selic tem influências positivas sobre o investimento, o que indica a peculiaridade desse período e leva à indagação se existe uma relação de cointegração entre as taxas de lucro empresariais 
e a proxy para a financeirização. Isso seria uma interpretação plausível e compatível com a hipótese do artigo: nesse período, as empresas não conseguem rentabilidade que justifique a alocação produtiva dos recursos, então seus ganhos ou sua poupança são absorvidos pela alocação financeira não produtiva. Daí a tendência à semiestagnação que se observou.

Sendo assim, testou-se a existência de cointegração entre as duas séries sugeridas. Tanto pelo procedimento de Johansen quanto pelo procedimento de Engle e Granger há a indicação de que as séries da rentabilidade e do fator acumulado da Selic possuem uma relação de equilíbrio de longo prazo, confirmando a hipótese anteriormente sugerida.

$\mathrm{Na}$ segunda fase, as séries são estacionárias, sendo possível apenas encontrar a elasticidade de curto prazo entre as variáveis, que estão dispostas na Tabela 2.

Tabela 2: Equação da acumulação de capital (2004-2008)

\begin{tabular}{ccccc}
\hline Variável & Coef. & Erro-padrão & Estatística t & Prob. \\
\hline F & -1.013918 & 0.260603 & -3.890666 & 0.0014 \\
R & 0.617383 & 0.301083 & 2.050543 & 0.0582 \\
U & 0.133778 & 1.151303 & 0.116197 & 0.9090 \\
C & 5.562323 & 6.125306 & 0.908089 & 0.3782 \\
\hline
\end{tabular}

Fonte: Elaboração própria.

Nesse caso, a renda de juros capitalizada, estimada pelo fator acumulado da taxa Selic, influencia negativamente a taxa de investimento, comprovando a relação negativa entre essas duas variáveis. Isso ocorre porque a taxa de acumulação de capital fixo produtivo volta a crescer justamente quando esse indicador sintético de rentabilidade financeira (Fator acumulado da Selic/ Kprod) começou a cair, isto é, pós-2004, significando que menos ganho financeiro induz à maior alocação produtiva do capital.

Além disso, é possível observar que a taxa de lucro surge como o principal determinante da taxa de acumulação (como previsto pelas teorias neoestruturalistas), ao mesmo tempo em que o nível de utilização da capacidade produtiva instalada parece não ter tido grande influência, haja vista que o coeficiente estimado relativo a essa variável é estatisticamente insignificante no período estudado. Já a taxa de lucro, que é justamente a empresarial, aquela calculada com o lucro retido pelas empresas (que é o que realmente conta para as decisões de investimento) parece ser o principalmente determinante positivo da taxa de acumulação de capital no período 2004-2009.

\section{CONCLUSÃO - AS CONSEQUENCIAS MACROECONÔMICAS DA FINANCEIRIZAÇÃO}

O padrão de financeirização vigente na economia brasileira difere do observado em países desenvolvidos, onde as taxas de juros são muito baixas e parcelas 
consideráveis da população dispõem de amplo acesso a ativos financeiros e, particularmente, aos mercados de capitais. No Brasil, a dívida pública interna tornou-se o principal eixo da acumulação rentista-patrimonial e a base da subordinação das finanças públicas às pressões dos mercados financeiros globais. Em consequência, a autonomia da política econômica é significativamente reduzida e sua formatação e gestão encontram-se permanentemente monitoradas pelas expectativas e racionalidade inerentes à revalorização financeira dos capitais. Uma estratégia de aceleração do crescimento econômico e de geração de emprego encontra, portanto, limites que lhes são estruturais ou endógenos no atual regime de crescimento brasileiro. Em contrapartida, a carga tributária tem crescido para responder à punção rentista exercida pelos detentores de capital e credores do Estado, e não para garantir o financiamento necessário dos gastos sociais ou promover o investimento público e demais funções que lhes são prerrogativas. Portanto, a financeirização reproduz os limites estruturais ao desenvolvimento econômico brasileiro.

No entanto, o processo de financeirização da economia brasileira compartilha de três características básicas com o seu homólogo em países desenvolvidos: i) aprofunda a concentração funcional da renda em favor dos lucros e em detrimento dos salários; e ii) reduz a taxa de acumulação de capital fixo produtivo, mantendo-a em um ritmo incompatível com o crescimento econômico forte e sustentável; iii) eleva o poder político das classes rentistas e dos detentores de capital sobre o aparelho de Estado, influenciando a formatação e a gestão da política econômica de acordo com as demandas e os interesses imediatos desses agentes econômicos.

A vigência de um regime macroeconômico subordinado à acumulação rentista-financeira não implica, necessariamente, a impossibilidade de crescimento econômico ou que a economia estará inevitavelmente condenada à quase estagnação. $\mathrm{O}$ que as evidências empíricas revelam para os países sujeitos a um processo de financeirização é que suas economias não se mostram capazes de crescer a taxas elevadas e sustentáveis, pois tais regimes são muito sensíveis ao perfil de distribuição de renda (fator de mercado interno) e às mudanças de cenário internacional (fator de mercado externo), além de provocarem a contaminação das expectativas dos empresários pelas avaliações curto-prazistas dos mercados financeiros. Afinal, parte expressiva das grandes empresas produtivas tem sua estrutura de ativos comprometida com operações financeiras.

No regime de crescimento do período 1991-2003, o lucro empresarial praticamente se confunde com o lucro não operacional. As firmas, em razão do ambiente desfavorável ao investimento produtivo ${ }^{2}$, optam, defensivamente, por alocar suas poupanças em ativos financeiros. Essa possibilidade decorre da macroestrutura institucional que emergiu do processo de liberalização comercial e financeira dos anos 1990, que implicou a permanência de taxas de juros reais muito elevadas e na pro-

\footnotetext{
${ }^{2}$ Destaque-se que esse período caracterizou-se por grande volatilidade dos fluxos de capitais e pela instabilidade macroeconômica provocada por uma sucessão de crises financeiras (México, 1995; Ásia, 1997; Rússia, 1998; e Brasil, 1999).
} 
liferação de produtos financeiros de alta liquidez e rentabilidade, com baixo risco, vis-à-vis, à imobilização dos recursos no setor produtivo. Dessa forma, conseguem obter ganhos significativos sem terem de expandir a parte imobilizada de seu capital e, portanto, sem que a formação bruta de capital fixo cresça o suficiente para elevar a taxa de crescimento econômico. Concomitantemente, observa-se a expansão rápida da dívida pública interna indexada à taxa de juros Selic, convertendo-a num dos principais eixos da acumulação rentista-patrimonial no país. Isso explica as tendências estagnacionistas observadas nesse período e permite a interpretação de que o regime de acumulação então vigente era do tipo "finance-dominated accumulation regime", de acordo com a denominação proposta por Stockhammer (2007). Nesse primeiro período, a financeirização bloqueia a taxa de acumulação de capital fixo produtivo e torna o regime de crescimento estagnante.

No período 2004-2008, a taxa de lucro empresarial nitidamente supera o ganho financeiro, induzindo à alocação diretamente produtiva das poupanças das firmas, daí as maiores taxas de crescimento econômico. A formação bruta de capital fixo volta a crescer, puxando a taxa de acumulação de capital. O sentido em que o novo regime de crescimento se classifica como um finance-led growth justifica-se de duas maneiras: i) a norma de rentabilidade financeira comanda as decisões de alocação de capital, e então as expectativas de investimento produtivo, tanto nesse quanto no primeiro período. Porém, a partir de 2004, além da rentabilidade real do capital fixo produtivo $(\mathrm{R})$ ter entrado em uma tendência de crescimento $^{3}$, o ganho financeiro paralelamente declina, o que promove o investimento e o crescimento econômico; ii) no entanto, a magnitude das taxas de crescimento econômico e sua sustentabilidade continuam sendo atributos dependentes da norma de rentabilidade financeira real que a alocação não produtiva oferece ostensivamente às empresas e aos detentores de capital. Portanto, nesse segundo período, a financeirização permite o surgimento de um regime de crescimento econômico a taxas moderadas, apesar de permanecerem significativamente abaixo da média dos demais emergentes. Em todo caso, o regime evolui "comandado" pelas expectativas e pela racionalidade inerentes à revalorização dos capitais na circulação financeira, o que o caracteriza como um finance-led growth regime. A rentabilidade real de referência encontra-se na órbita financeira e não nas atividades diretamente produtivas, que se estruturam como instância subordinada. As finanças não estão, portanto, a serviço da acumulação produtiva e do crescimento econômico, mas se estruturam, prioritariamente, para a acumulação financeira e patrimonial.

Para países em desenvolvimento, a financeirização torna-se um entrave estrutural ainda maior porque provoca a reconcentração funcional da renda em favor dos detentores de capital sem necessariamente induzi-los a elevar o nível de investimento produtivo, fator básico da geração de emprego e de renda. Trabalhos fu-

\footnotetext{
${ }^{3}$ Entre as razões para a recuperação da taxa de lucro empresarial encontram-se a elevação da demanda externa pelas commodities brasileiras e a melhora das condições de mercado interno de consumo.
} 
turos deverão propor o desenvolvimento de indicadores de financeirização para o nível da firma e setorial, bem como a formulação de um modelo macroeconômico teórico que possa elucidar as condições de estabilidade dinâmica do regime de crescimento. A crise americana atual e seus impactos sobre a economia brasileira abrem um importante campo para pesquisas sobre as características e viabilidade de tais regimes.

\section{REFERÊNCIAS BIBLIOGRÁFICAS}

AGLIETTA, Michel (2008) La Crise. Pourquoi en est-on arrivé là? Comment en sortir? Éditions Michalon.

.(1999) La Globalisation Financière. Paris: La Découverte, collection Repères, 1999.

ARROW K-J e DEBREU G, [1954], “Existence of an Equilibrium for a Competitive Economy,” Econometrica, p-262/290.

BOYER, Robert. La politique a l'ere de la mondialisation et de la finance: le point sur quelques recherches regulationnistes. CEPREMAP, Paris, 1999.

. Deux défis pour le XXI ${ }^{\mathrm{e}}$ siècle: discipliner la finance et organiser l'internationalisation. CEPREMAP n²000-08, Paris, 2000.

. Is a finance-led growth regime a viable alternative to Fordism? A preliminary analysis. Economy and Society. Volume 29 number 1 february 2000,

. Théorie de la regulation. Éditions La Découverte, collection Repères, Paris, 2004;

BRAGA Souza [1998], "Financeirização global: o padrão sistêmico de riqueza do capitalismo contemporâneo", in Tavares, Eds, "Poder e dinheiro", Editora Vozes, 6a edição, p-195/242.

BRAGA Souza [1985], "Temporalidade da riqueza: teoria da dinâmica e financeirização do capitalismo, Tese, Unicamp, São Paulo.

CHESNAIS, François. La théorie du régime d'accumulation financiarisé: contenu, portée et interrogations. Forum de La Régulation, Paris, 2003. . (1996), “A mundialização do capital”, São Paulo, Xamã.

CORIAT, Benjamin. Moves towards finance-led capitalism: the French case in The Hardship of Nations - Exploring the Paths of Modern Capitalism. Edwar Elgar Publishing, Cheltenham, UK Northampton, MA, USA 2006;

EPSTEIN, Gerald. Financialization, rentier interests and Central Bank Policy. PERI Conference on "Financialization of the World Economy", December, 2001;

EPSTEIN, Gerald A. and JAYADEV, Arjun. The Rise of Rentier Incomes in OECD Countries: Financialization, Central Bank Policy and Labor Solidarity. In Financialization and the World Economy, edited by Gerald Epstein of the Political Economy Research Institute. Forthcoming from Edward Elgar, spring. 2005;

FLOOD, R.P. and GARBER P.M [1980], "Market Fundamentals versus Price Level Bubbbles: The First Tests," Journal of Political Economy, 88, p-745 /770

GUTTMANN, Robert. A Primer on Finance-Led Capitalism and Its Crisis. Revue de la régulation Capitalisme, Institutions, Pouvoirs, n³/4, 2008.

HERMANN, Jennifer. "Financial Structure and Financing Models: The Brazilian Experience over the 1964-1997 Period”. In: JLAS, pp 71-114, 2002.

HILFERDING Rudolf[1963], El capital financeiro. Madrid: Editorial Tecnos.

KRIPPNER, Greta R. The financialization of the American economy, Socio-Economic Review, 173 208, 2005.

MARQUETTI, Adalmir. Nota metodológica sobre as informações estatísticas utilizadas na análise do padrão de progresso técnico na economia brasileira, 1950-1998. Instituto de Economia/ PUC-RS, 2003. 
. The rate of profit in the Brazilian economy 1953-2003, in Actuel Marx, Paris, 2005;

MINSKY, H. Can "it" Happen Again? Essays on Instability and Finance, M. E Sharpe, Inc., Armonk, New York, 1982.

ORHANGAZI, Özgür. Financialisation and capital accumulation in the non-financial corporate sector. A theoretical and empirical investigation on the US economy: 1973-2003. Cambridge Journal of Economics 1 of 24, 2008.

PALLEY, Thomas. Financialization: what it is and why it matters. Working Papers n. 525, The Levy Economics Institut of Bard College. December, 2007;

. (2005), "As grandes empresas fragilizadas pela finança”, in F. Chesnais, "A finança mundializada", Boitempo Editorial.

SERFATI Claude (1999), "O papel ativo dos grupos predominantemente industrias na financeirizaçao da economia”, in F. Chesnais “A mundialização financeira”, Xama Editora.

SKOTT, Peter and RYOO, Soon. Macroeconomic Implications of financialization. University of Massachusetts Amherst, Department of Economics, Working Paper 2007-08, 2007.

STOCKHAMMER, E. Financialization and the slowdown of accumulation. Cambridge Journal of Economics, n. 28, p. 719-741, 2004.

. Some stylized facts on the finance-dominate accumulation regime. Political Economy Research Institut - PERI - University of Massachussets Anherst, 2.

Anexo: Figura 1 - Macroestrutura da financeirização por juros em setores e classes socais na economia brasileira

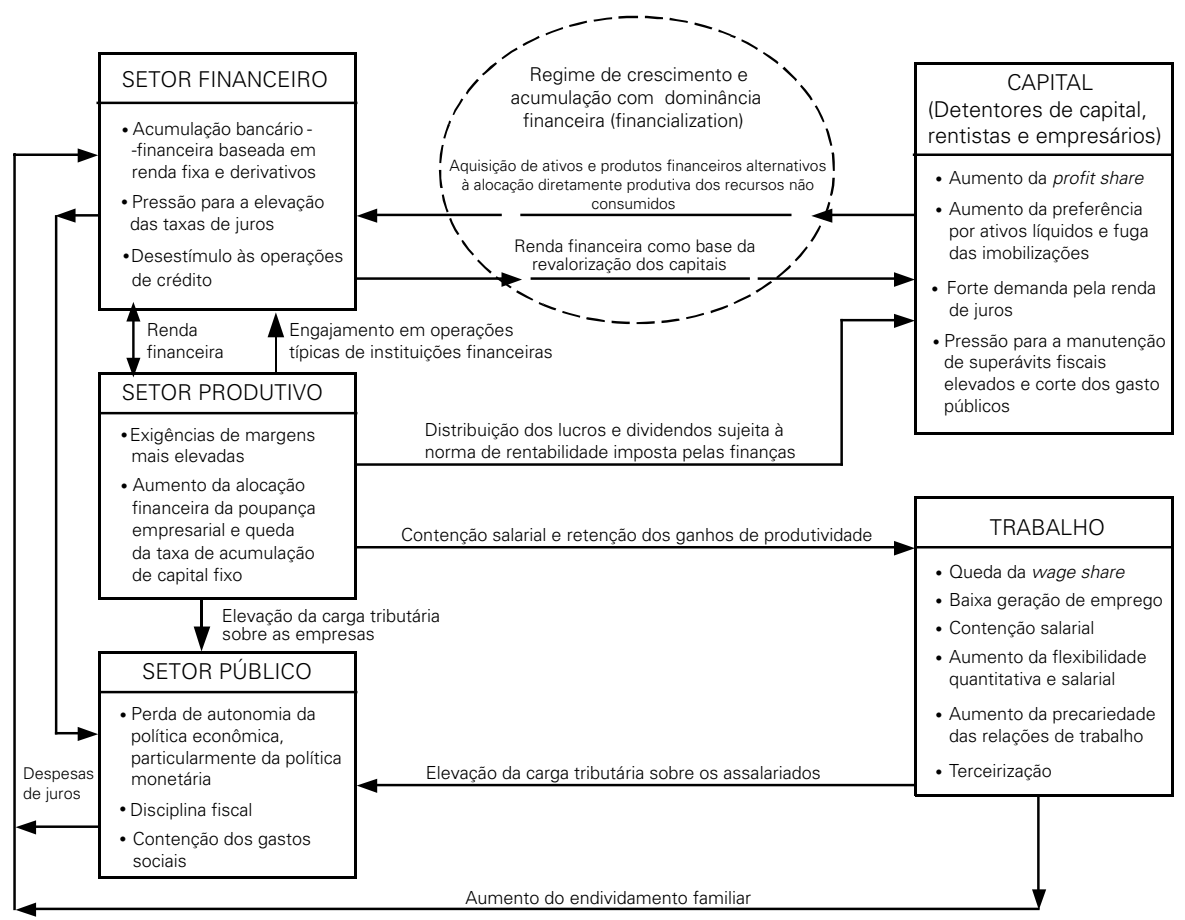


Apêndice

Quadro 1: Lista de variáveis da pesquisa, metodologia e construção

\begin{tabular}{|c|c|c|}
\hline Sigla & Comentário & Fonte \\
\hline$A F$ & $\begin{array}{l}\text { Total de ativos financeiros não monetários, obtido pela diferença entre os } \\
\text { agregados monetários } M 4 \text { e } M 1 \text {. }\end{array}$ & $\mathrm{BCB}$ \\
\hline Kprod & $\begin{array}{l}\text { Estoque de capital fixo produtivo. Corresponde à soma do estoque em } \\
\text { máquinas e equipamentos mais o estoque em construções não residenciais. }\end{array}$ & IPEADATA \\
\hline AF/Kprod & $\begin{array}{l}\text { É um indicador macroeconômico de financeirização - taxa de financeiriza- } \\
\text { ção. No período } 1966-1980 \text {, de alto crescimento econômico brasileiro, este } \\
\text { indicador era de } 7 \% \text {. Atualmente atinge a cifra de } 21 \% \text {. }\end{array}$ & IPEADATA \\
\hline VA financeiro & $\begin{array}{l}\text { Valor adicionado financeiro. Calculado pela método SIFIM, isto é, estima-se } \\
\text { a contribuição do setor bancário-financeiro ao PIB através dos serviços de } \\
\text { intermediação financeiras indiretamente medidos, segundo metodologia } \\
\text { recomendada pelo System of National Accounts da ONU. }\end{array}$ & IBGE \\
\hline $\begin{array}{l}\text { Taxa de lucro bruto } \\
\text { macroeconômico }\end{array}$ & $\begin{array}{l}\text { Corresponde à massa de lucro bruto macroeconômico dividida pelo estoque } \\
\text { de capital fixo produtivo total (Kprod) da economia brasileira. A massa de lu- } \\
\text { cro bruto foi calculada pela diferença entre o PIB a custo de fatores e a mas- } \\
\text { sa salarial. Esta última incluiu a remuneração dos empregados e dos trabalha- } \\
\text { dores por conta própria e as contribuições sociais. Para as décadas de 1960, } \\
1970 \text { e 1980, foram utilizadas as estimativas elaboradas por Marquetti (2003), } \\
\text { para os anos em que não se dispunha de dados oficiais para os salários. }\end{array}$ & $\begin{array}{l}\text { IBGE, } \\
\text { IPEADATA } \\
\text { e Marquetti } \\
\text { (2003) }\end{array}$ \\
\hline $\begin{array}{l}\text { Taxa de lucro } \\
\text { empresarial }(R)\end{array}$ & $\begin{array}{l}\text { O lucro empresarial é o lucro retido pelas empresas e corresponde à parcela } \\
\text { do lucro macroeconômico não distribuída aos acionistas e proprietários. Foi } \\
\text { calculado pela diferença entre o lucro macroeconômico e a renda disponível } \\
\text { bruta das famílias detentoras de capital. Esta, por sua vez, foi calculada } \\
\text { deduzindo-se a renda salarial da renda disponível bruta para o total da eco- } \\
\text { nomia brasileira. }\end{array}$ & $\begin{array}{l}\text { IBGE, } \\
\text { IPEADATA } \\
\text { e Marquetti } \\
\text { (2003) }\end{array}$ \\
\hline $\begin{array}{l}\text { Taxa de acumulação } \\
\text { de capital fixo } \\
\text { produtivo }(G)\end{array}$ & $\begin{array}{l}\text { Corresponde à razão entre a formação bruta de capital fixo ( } F B C F \text { e o esto- } \\
\text { que de capital fixo produtivo (Kprod) disponível à economia brasileira. }\end{array}$ & IPEADATA \\
\hline $\begin{array}{l}\text { Proxy da } \\
\text { rentabilidade } \\
\text { financeira }(F)\end{array}$ & $\begin{array}{l}\text { É a razão entre o fator acumulado da taxa Selic real e o estoque de capital fi- } \\
\text { xo produtivo (Kprod). Expressa a rentabilidade financeira, com base na renda } \\
\text { de juros capitalizada. Quanto maior sua magnitude, relativamente ao volume } \\
\text { de capital imobilizado em máquinas e equipamentos pelas empresas, menor } \\
\text { seria o estímulo para ampliarem esse volume ou aumentarem a taxa de uti- } \\
\text { lização da capacidade produtiva instalada. Caso em que seria melhor aplicar } \\
\text { suas receitas em ativos financeiros. }\end{array}$ & $\begin{array}{l}\text { BCB e } \\
\text { IPEADATA }\end{array}$ \\
\hline $\begin{array}{l}\text { Nível de utilização da } \\
\text { capacidade produtiva } \\
\text { instalada }(U)\end{array}$ & $\begin{array}{l}\text { Correspondem às séries dessazonalizadas produzidas pela Confederação } \\
\text { Nacional da Indústria (CNI). }\end{array}$ & IPEADATA \\
\hline $\begin{array}{l}\text { Proporção } \\
\text { investida do lucro } \\
\text { macroeconômico }\end{array}$ & $\begin{array}{l}\text { É estimada pela razão entre FBCF e a massa de lucro. É uma proxy da } \\
\text { poupança empresarial que foi alocada em investimento produtivo. }\end{array}$ & IBGE \\
\hline Taxa de inflação & $\begin{array}{l}\text { Foi utilizada a série do Índice Geral de Preços — disponibilidade interna da } \\
\text { Fundação Getulio Vargas. }\end{array}$ & IPEADATA \\
\hline $\begin{array}{l}\text { Rendimento } \\
\text { financeiro acumulado }\end{array}$ & $\begin{array}{l}\text { Corresponde à acumulação dos fluxos de renda financeira gerados a } \\
\text { partir das diferenças entre os estoques totais dos ativos financeiros } \\
\text { não monetários }(M 4-M 1) \text {, isto é, } A F_{t-2}-A F_{t-1} \text { e deflacionados pelo IGP-DI. }\end{array}$ & IPEADATA \\
\hline $\begin{array}{l}\text { Fator acumulado da } \\
\text { taxa Selic real }\end{array}$ & $\begin{array}{l}\text { Trata-se da capitalização composta da taxa de juros Selic real, calculada } \\
\text { usando-se como deflator o IGP-DI da FGV. Usa-se o seguinte produtório: } \\
\left(1+\text { TaxaSelic }_{t+1}\right) \cdot\left(1+\text { TaxaSelic }_{t+2}\right) \cdot\left(1+\text { TaxaSelic }_{t+3}\right) \ldots\left(1+\text { TaxaSelic }_{t+n}\right) .\end{array}$ & IPEADATA \\
\hline $\begin{array}{l}\text { Reservas } \\
\text { internacionais }\end{array}$ & $\begin{array}{l}\text { Série das reservas internacionais - liquidez internacional - gerada pelo Ban- } \\
\text { co Central do Brasil (BCB). }\end{array}$ & IPEADATA \\
\hline
\end{tabular}

